Dhaka Univ. J. Biol. Sci. 28(2): 167-176, 2019 (July)

\title{
DIVERSITY IN EXTERNAL MORPHOLOGY, SEX COMB AND DEVELOPMENTAL STAGES OF THREE DROSOPHILA SPECIES OF MELANOGASTER GROUP
}

\author{
Mohammad Shamimul Alam, Md. Nazmul Hoque, Mousumi Akter \\ AND REZA MD. SHAHJAHAN \\ Genetics and Molecular Biology Laboratory, Department of Zoology, \\ University of Dhaka, Bangladesh
}

Key words: Diversity, Sex comb, Morphology, Drosophila species

\begin{abstract}
Samples of Drosophila species were collected from some selected sites (viz., Dohar Upazila of Dhaka Division, Hironpoint of the Sundarbans, Satchori of Sylhet Division) of Bangladesh and these were cultured in the laboratory to study developmental stages, external morphological traits and sex comb. They were identified as D. melanogaster, D. ananassae and D. bipectinata. The sex comb teeth number and arrangement were distinct for all three species. D. melanogaster had one row of 10 - 11 teeth in the sex comb. D. ananassae had eight rows of teeth in the sex comb possessing 32 - 33 teeth in total. D. bipectinata had 2 - 3 rows of teeth in the sex comb and total teeth number varied from 11 to 15 . Among three species, sex comb teeth number of D. bipectinata varied most. Eleven different patterns $(n=20)$ in sex comb were observed in D. bipectinata indicating significant diversity within species. Variation in pupation sites among three species was also observed in the laboratory condition. D. bipectinata pupated on the food medium, whereas other two species pupated on the vial wall. Thus, diversity among these three species of Drosophila was documented which could be utilized as bioindicator in future.
\end{abstract}

\section{Introduction}

Drosophila species are commonly known as fruit fly or vinegar fly ${ }^{(1)}$. It is mainly used as a model organism in biomedical research. Drosophila spp. has been used for the study of human genetic diseases, mechanisms of development, cell biology, neurobiology, behavior, physiology and evolution (2). About $75 \%$ of known human disease genes have a recognizable match in the genome of fruit flies. It has been reported that 548 genes of Drosophila are related to human disease causing genes ${ }^{(3)}$. Besides, chromosomal diversity is found to decrease in Drosophila due to global warming(4). It can also be a pollution indicator since the fruits (whether grown organically or inorganically) they feed on have impact on their fertility, longevity, activity and stress resistance(5). Thus, diversity among the species of Drosophila might indicate overall environmental condition of a region.

*Author of correspondence: <shamimul@du.ac.bd>. 
In Bangladesh, a very few research work on Drosophila have been reported so far. Ten Drosophila species were recorded from Bangladesh ${ }^{(6-7)}$. Since then, no other report could be retrieved. So, it has become a priority task to collect, identify and record the Drosophila species found in this region for any future reference required to monitor the environmental impact on biological systems.

Morphological identification of Drosophila species is based on body coloration, sex comb teeth number and arrangement, bristle numbers and location, genital region, and developmental stages( ${ }^{(8)}$. Among all the characteristics, sex comb is a male-specific morphological structure that plays major role in species-specific mating, and thus in species identification. The male sex comb is an array of specialized bristles on the forelegs. It is highly variable secondary sexual trait of the melanogaster species groups of Drosophila ${ }^{(9-10)}$.

Change in the fly environment affects development immediately. So, egg-laying, larval instars and behavior, pupa and pupation site preferences are also important traits of study. Therefore, in the present study, the collected samples of Drosophila species were maintained in the laboratory rearing to study development, and external morphological traits with special emphasis on sex comb teeth number and patterns.

\section{Methods and Materials}

To collect Drosophila from nature, a catch box of plastic jar with partially cut lid was made. Yeasted food was used as bait. When flies entered the plastic jar, they were trapped by covering the open portion of the jar by the lid. The lid was fitted with a food vial beforehand. Thus, flies were collected in the food vials where they were cultured and maintained for subsequent experiments. Standard fly food media (semolina, yeast, sugar, glucose and agar) was used in this case. The flies were reared in room temperature $(25 \pm$ $2^{\circ} \mathrm{C}$ ) and humidity could not be recorded. Drosophila flies were collected from nine different locations. Total three species strains collected from Dohar, Dhaka Division

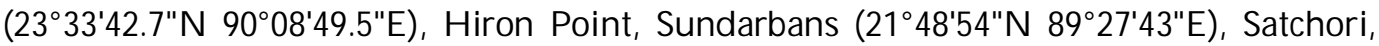
Sylhet $\left(24^{\circ} 07^{\prime} 12^{\prime \prime} \mathrm{N} 91^{\circ} 27^{\prime} 03^{\prime \prime} \mathrm{E}\right)$ were maintained in the laboratory for the study.

External morphology, sex comb arrangement and developmental stages of all the species strains were observed and studied under a stereomicroscope (Leica ZOOM 2000). For the analysis of sex comb, both stereo and compound microscopes were utilized. To ascertain variations in sex comb, at least 20 individual flies were studied from each fly species. To observe developmental stages, adult flies were allowed to lay eggs on egglaying plates (made of agar, apple juice, sucrose and water). First instar larvae were collected from egg-laying plates after $24 \mathrm{hrs}$ and transferred to standard food media for their subsequent development up to adult. Some images of Hiron Point strain (HP) was captured by using a 3D camera (JVC digital camera KY-F75U, 3-CCD). All other images 
were taken by using a hand-held digital camera mounted on the eyepiece of the microscope. Drosophila species were identified using published morphological keys ${ }^{(8)}$.

\section{Results and Discussion}

Among the collected strains in the present study, only three have been characterized and identified as D. ananassae (SC), D. bipectinata (DR) and D. melanogaster (HP) (Fig. 1, Table 1). All these species belong to the melanogaster group. Among them, D. ananassae and $D$. bipectinata are closer belonging to the ananassae subgroup of melanogaster group. Variations in external morphological phenotypes (body shape, size and color, abdominal region and sex comb) observed among these species have been presented in the Fig. 1 and Table 1. More species of Drosophila have been reported from Bangladesh previously. Ten Drosophila species have been reported from Bangladesh, which are D. kikkawai, D. ananassae, D. repleta, D. takahashii, D. pseudoananassae, D. bipectinata, D. melanogaster, D. buskii, D. latifshahi and Scaptodrosophila meijerei(6-7). The three species in question were also listed in the previous reports ${ }^{(6)}$.

Table 1. Distinguishing characteristics of D. melanogaster, D. ananassae and D. bipectinata.

\begin{tabular}{|c|c|c|c|}
\hline Characteristics & D. melanogaster & D. ananassae & D. bipectinata \\
\hline Body length & $2.5-3 \mathrm{~mm}$ & $>3 \mathrm{~mm}$ & $<3 \mathrm{~mm}$ \\
\hline Body color & Yellow brown & Yellow light brown & Pale brown \\
\hline Male abdomen & $\begin{array}{l}\text { A distinct black patch } \\
\text { present at the } \\
\text { abdomen }\end{array}$ & $\begin{array}{l}\text { Unbroken abdominal } \\
\text { pigmentation present }\end{array}$ & $\begin{array}{l}\text { Transverse black } \\
\text { rings present across } \\
\text { the abdomen. }\end{array}$ \\
\hline Third instar larva length & $<4.5 \mathrm{~mm}$ & $<4.5 \mathrm{~mm}$ & $4.5-5 \mathrm{~mm}$ \\
\hline $\begin{array}{l}\text { Third instar larval crawling } \\
\text { on the wall of the vials }\end{array}$ & Yes & $\begin{array}{l}\text { Less than } \\
\text { D. melanogaster }\end{array}$ & No or rare \\
\hline $\begin{array}{l}\text { Row and sex comb teeth } \\
\text { number (SCTN) }\end{array}$ & $\begin{array}{l}\text { One row and } \\
\text { SCTN } 10-11\end{array}$ & $\begin{array}{l}8 \text { rows and } \\
\text { SCTN 32-33 }\end{array}$ & $\begin{array}{l}2-3 \text { rows and } \\
\text { SCTN } 11-15\end{array}$ \\
\hline $\begin{array}{l}\text { Oviposition on egg laying } \\
\text { plate }\end{array}$ & $\begin{array}{l}\text { On the surface of agar } \\
\text { medium }\end{array}$ & $\begin{array}{l}\text { On the surface of agar } \\
\text { medium }\end{array}$ & $\begin{array}{l}\text { Into the egg-laying } \\
\text { agar medium }\end{array}$ \\
\hline $\begin{array}{l}\text { Show negative geotaxis } \\
\text { behavior (data not shown) }\end{array}$ & $\begin{array}{l}\text { More than } D . \\
\text { ananassae and } \\
\text { D. bipectinata }\end{array}$ & $\begin{array}{l}\text { Less than } D \text {. } \\
\text { melanogaster and more } \\
\text { than } D \text {. bipectinata }\end{array}$ & $\begin{array}{l}\text { Less than } \\
\text { D. melanogaster and } \\
\text { D. ananassae }\end{array}$ \\
\hline Cold shock tolerance & $\begin{array}{l}\text { More than } \\
\text { D. ananassae and } \\
\text { D. bipectinata }\end{array}$ & $\begin{array}{l}\text { Less than } \\
\text { D. melanogaster and } \\
\text { D.biectinata }\end{array}$ & $\begin{array}{l}\text { Less than } \\
D . \text { melanogaster but } \\
\text { more than } D \text {. } \\
\text { ananassae }\end{array}$ \\
\hline Pupation takes place & $\begin{array}{l}\text { Mostly above the food } \\
\text { on the vials wall }\end{array}$ & $\begin{array}{l}\text { Both on the vial wall } \\
\text { and on food medium }\end{array}$ & $\begin{array}{l}\text { Mostly on the food } \\
\text { medium }\end{array}$ \\
\hline
\end{tabular}




\section{Drosophila melanogaster}

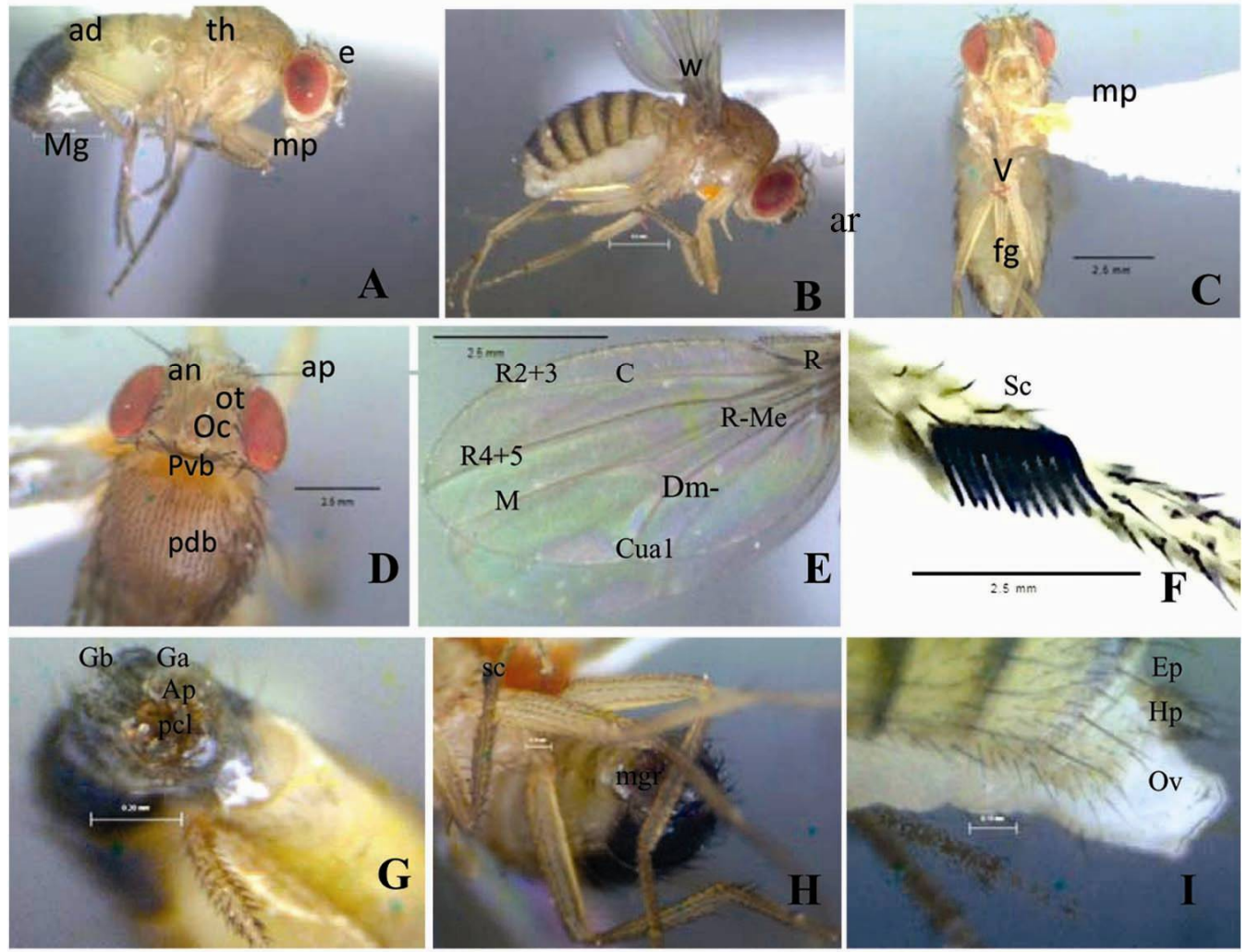

D. ananassae

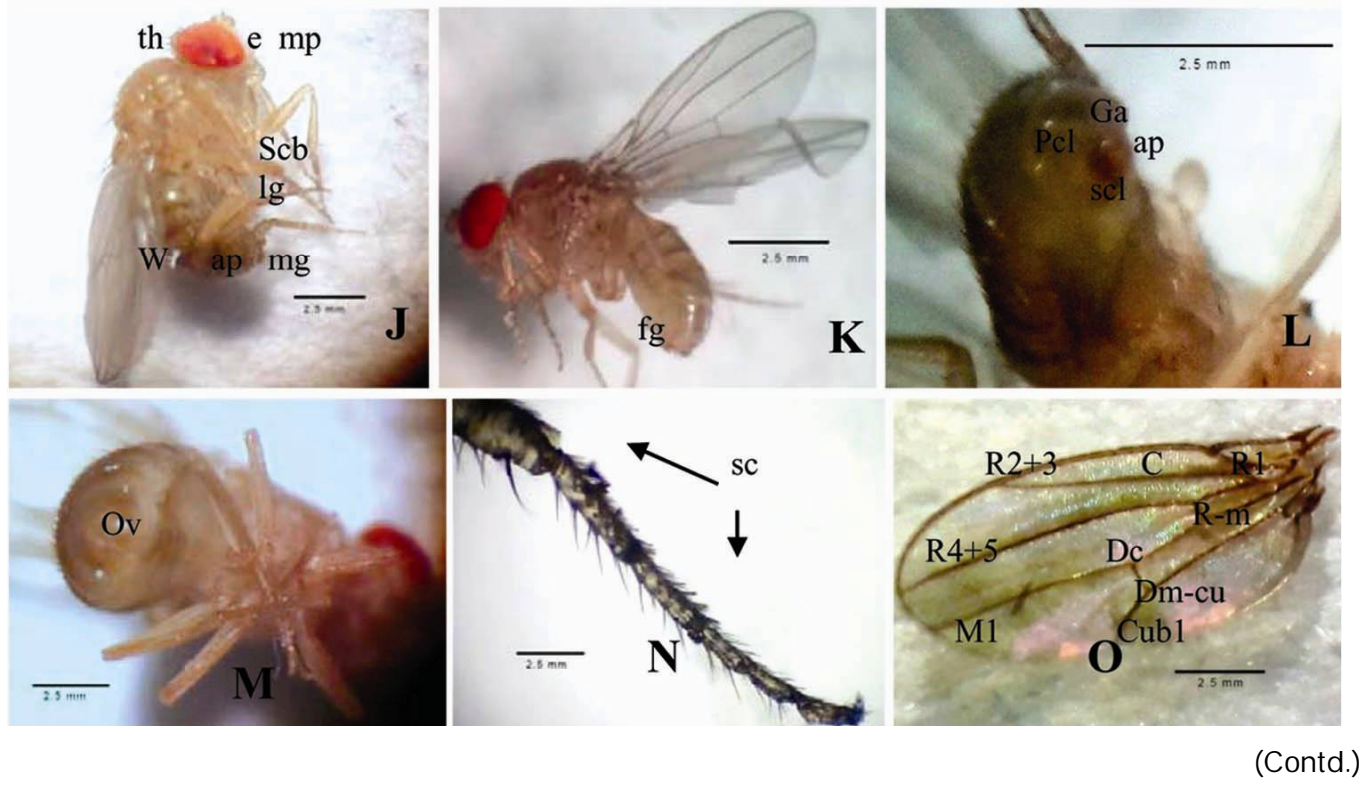




\section{D. bipectinata}

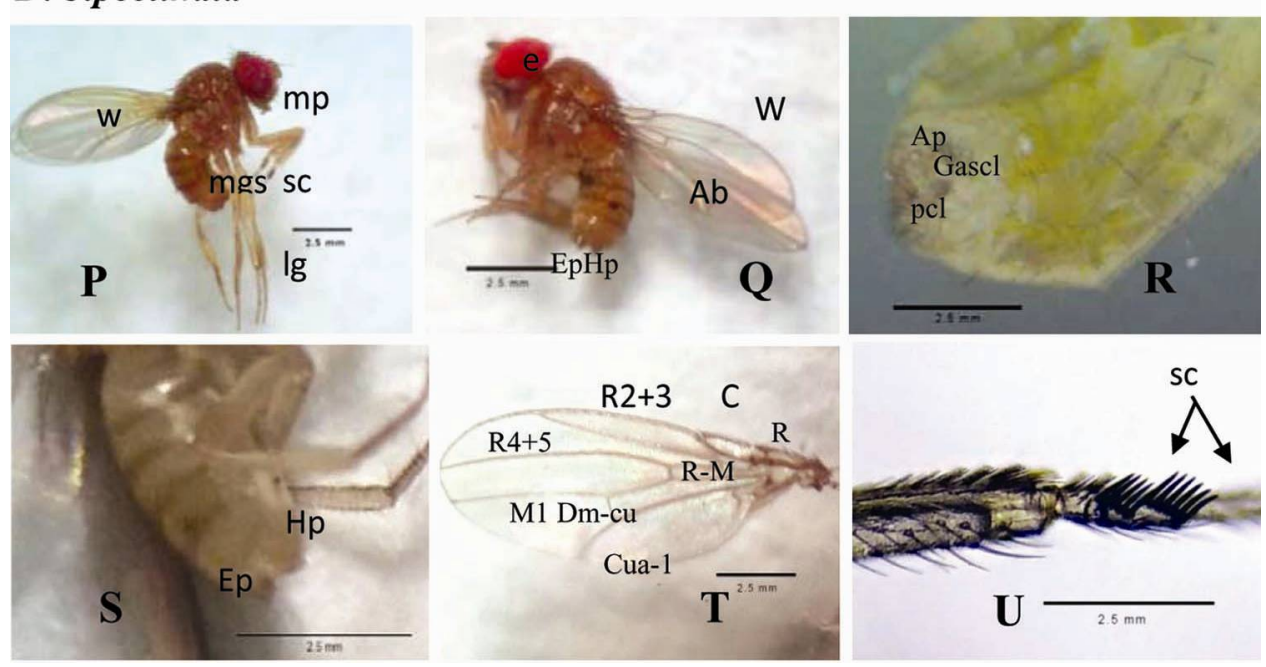

Fig. 1. Morphological characteristics of three Drosophila species - D. melamogaster $(\mathrm{A}=$ Male, $\mathrm{B}=$ Female, $\mathrm{C}=$ Ventral view of female, $\mathrm{D}=$ Head, $\mathrm{E}=$ Wing venation, $\mathrm{F}=\mathrm{Sex}$ comb arrangement, $\mathrm{G} \& \mathrm{H}=$ Male genital region, $\mathrm{I}=$ Female genital region); $D$. ananassae $(\mathrm{J}=$ Male, $\mathrm{k}=$ Female, $\mathrm{L}=$ Male genital region, $\mathrm{M}=$ Female genital region, $\mathrm{N}=$ Sex comb arrangement, $\mathrm{O}=$ Wing venation); and D. bipectinata $(\mathrm{P}=$ Male, $\mathrm{Q}=$ Female, $\mathrm{R}$ = Male genital region, $\mathrm{S}=$ Female genital region, $\mathrm{T}=$ Wing venation, $\mathrm{U}=\mathrm{Sex}$ comb). $\mathrm{ad}=$ Abdomen, $\mathrm{th}=$ Thorax, $\mathrm{e}=$ Compound eye, $\mathrm{mg}=$ Male genital, $\mathrm{mg} \mathrm{r}=$ Male genital region, $\mathrm{fg}=$ Female genital, $\mathrm{lg}=\mathrm{Legs}, \mathrm{w}$ $=$ Wings, $\mathrm{ar}=$ Arista, $\mathrm{mp}=$ Mouth parts, $\mathrm{v}=$ Ventral view, $\mathrm{an}=$ Antenna, $\mathrm{ap}=$ Arista plumase, ot $=$ Ocellar triangle, $\mathrm{oc}=$ Ocellus, $\mathrm{pvb}=$ Post vertical bristle, $\mathrm{pdb}=$ Posterior dorso-central bristles, $\mathrm{R} 2+3=$ Radius $2+3$, $\mathrm{R} 4+5=$ Radius $4+5, \mathrm{M}=$ Media1, $\mathrm{C}=$ Costa, $\mathrm{R}=$ Radius, $\mathrm{Cual}=\mathrm{Cubitus}$ anale1, $\mathrm{Dm}-\mathrm{Cu}=$ Distal medialcubital, $\mathrm{R}-\mathrm{Me}=$ Radial-media, $\mathrm{Sc}=\mathrm{Sex}$ comb, $\mathrm{Gb}=$ Genital bristles, $\mathrm{Ga}=$ Genital arch, $\mathrm{Ap}=$ Anal plate, $\mathrm{Pcl}=$ Primary clasper, $\mathrm{Scl}=$ Secondary clasper, $\mathrm{Ep}=$ Epiproct, $\mathrm{Hp}=$ Hypoproct, $\mathrm{Ov}=$ Oviscapt, $\mathrm{Scb}=\mathrm{Sex}$ comb bristles.

Study of sex comb patterns showed clear differences among three Drosophila spp. strains. In D. melanogaster, number of sex comb row is one (i.e. bearing one row of teeth) (Fig. 1F). It's sex comb is confined to only first tarsomere of the foreleg. The number of sex comb teeth (SCTN) did not vary much, either 10 or 11. First tarsal segment is reported to have a large sex comb bearing 11 black teeth arranged in one row ${ }^{(6)}$. Though variation is there, individuals with 11 black teeth have also been found in the present study. On the other hand, more variability in sex comb teeth number (e.g. $7-14^{(11)}$ and $7-13^{(12)}$ in $D$. melanogaster was reported previously.

In D. ananassae, eight rows of sex comb present. Total SCTN detected in D.ananassae was 32 - 33 (Fig. 2B). Out of 20 samples analyzed, only two patterns of sex comb teeth arrangement were found. The variability found in the present study is much less than that reported in previous studies ${ }^{(11-12)}$. SCTN in D. ananassae varies from $22-35^{(12)}$ to 31-35(13). The teeth number found in the present study falls within the range of that found in the previous studies. 
In $D$. bipectinata male, first tarsomere has 4-6 teeth in the proximal comb, and 5-8 teeth in the distal comb. On the other hand, second tarsomere bears 0-2 in the proximal comb and 0-1 in the distal comb. Eleven sex comb teeth arrangement patterns (out of 20 samples) have been detected in $D$. bipectinata and sex comb teeth number ranges from 10 to 15 (Fig. 2C-O and Table 2). Thus, sex comb teeth number and arrangement varied most in $D$. bipectinata compared to other two species of melanogaster group. The males of $D$. becptinata have two obliquely placed sex combs on metatarsal segment, upper comb with

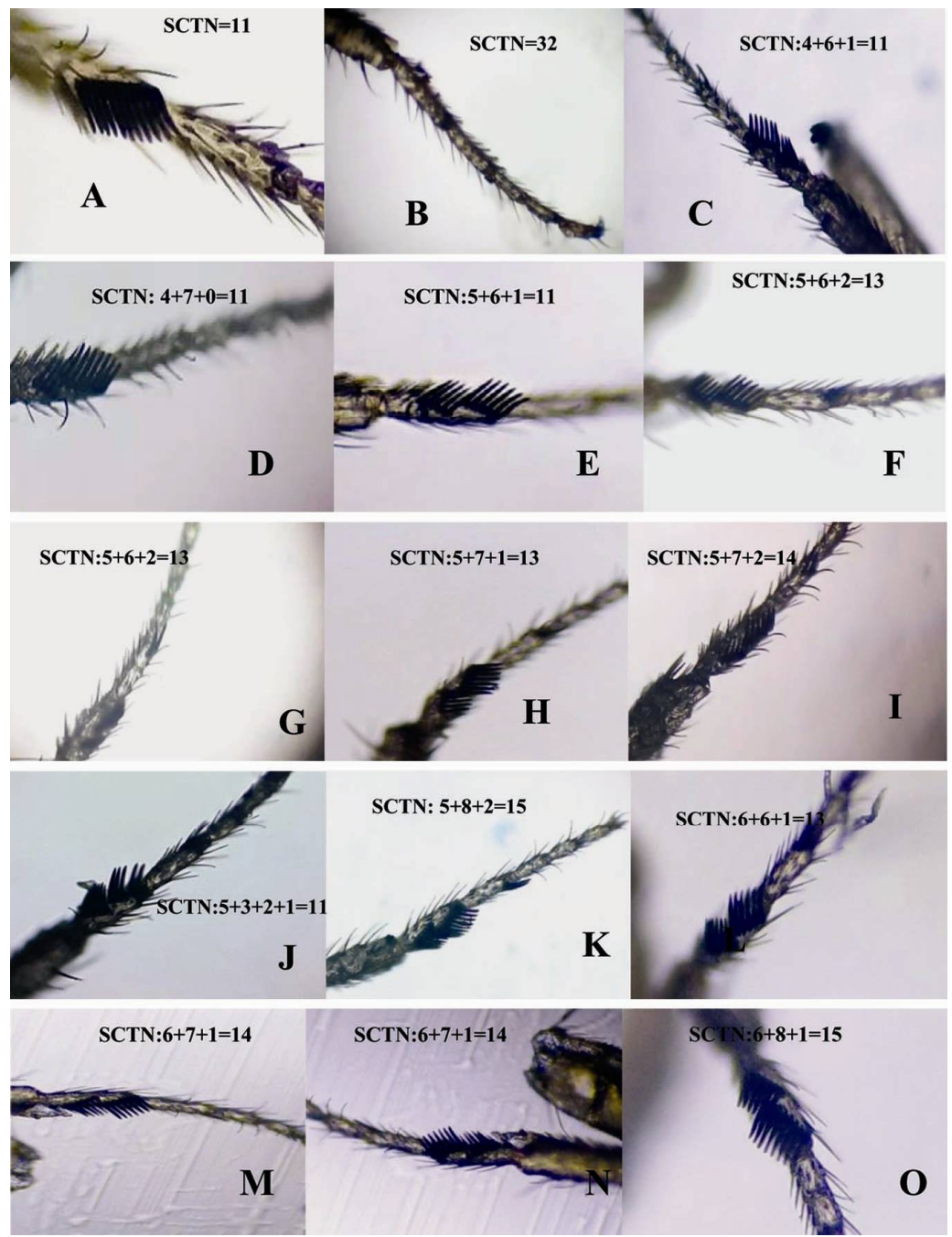

Fig. 2. Sex comb teeth arrangement patterns in three Drosophila species. (A) D. melanogaster, (B) D. ananassae, and (C-O) D. bipectinata. The sex comb teeth number (SCTN) formula indicates the number of teeth in the proximal comb of first tarsomere, distal comb of first tarsomere, and proximal comb of second tarsomere, respectively. 
Table 2. Sex comb teeth number and arrangement in D. bipectinata $(\mathrm{n}=20)$.

\begin{tabular}{|c|c|c|c|c|c|c|}
\hline \multirow{2}{*}{$\begin{array}{l}\text { Sex comb } \\
\text { patterns }\end{array}$} & \multicolumn{2}{|c|}{ First tarsomere } & \multicolumn{2}{|c|}{ Second tarsomere } & \multirow{2}{*}{$\begin{array}{l}\text { Total } \\
\text { SCTN }\end{array}$} & \multirow{2}{*}{$\begin{array}{c}\text { Claws } \\
\text { No. }\end{array}$} \\
\hline & $\begin{array}{c}\text { Proximal } \\
\text { comb }\end{array}$ & $\begin{array}{l}\text { Distal } \\
\text { comb }\end{array}$ & $\begin{array}{c}\text { Proximal } \\
\text { comb }\end{array}$ & $\begin{array}{l}\text { Distal } \\
\text { comb }\end{array}$ & & \\
\hline 1 & 4 & 6 & 1 & 0 & 11 & 1 \\
\hline 2 & 4 & 7 & 0 & 0 & 11 & 1 \\
\hline 3 & 5 & 6 & 1 & 0 & 12 & 1 \\
\hline 4 & 5 & 6 & 2 & 0 & 13 & 1 \\
\hline 5 & 5 & 7 & 1 & 0 & 13 & 1 \\
\hline 6 & 5 & 7 & 2 & 0 & 14 & 1 \\
\hline 7 & 5 & 3 & 2 & 1 & 11 & 1 \\
\hline 8 & 5 & 8 & 2 & 0 & 15 & 1 \\
\hline 9 & 6 & 6 & 1 & 0 & 13 & 1 \\
\hline 10 & 6 & 7 & 1 & 0 & 14 & 1 \\
\hline 11 & 6 & 8 & 1 & 0 & 15 & 1 \\
\hline
\end{tabular}
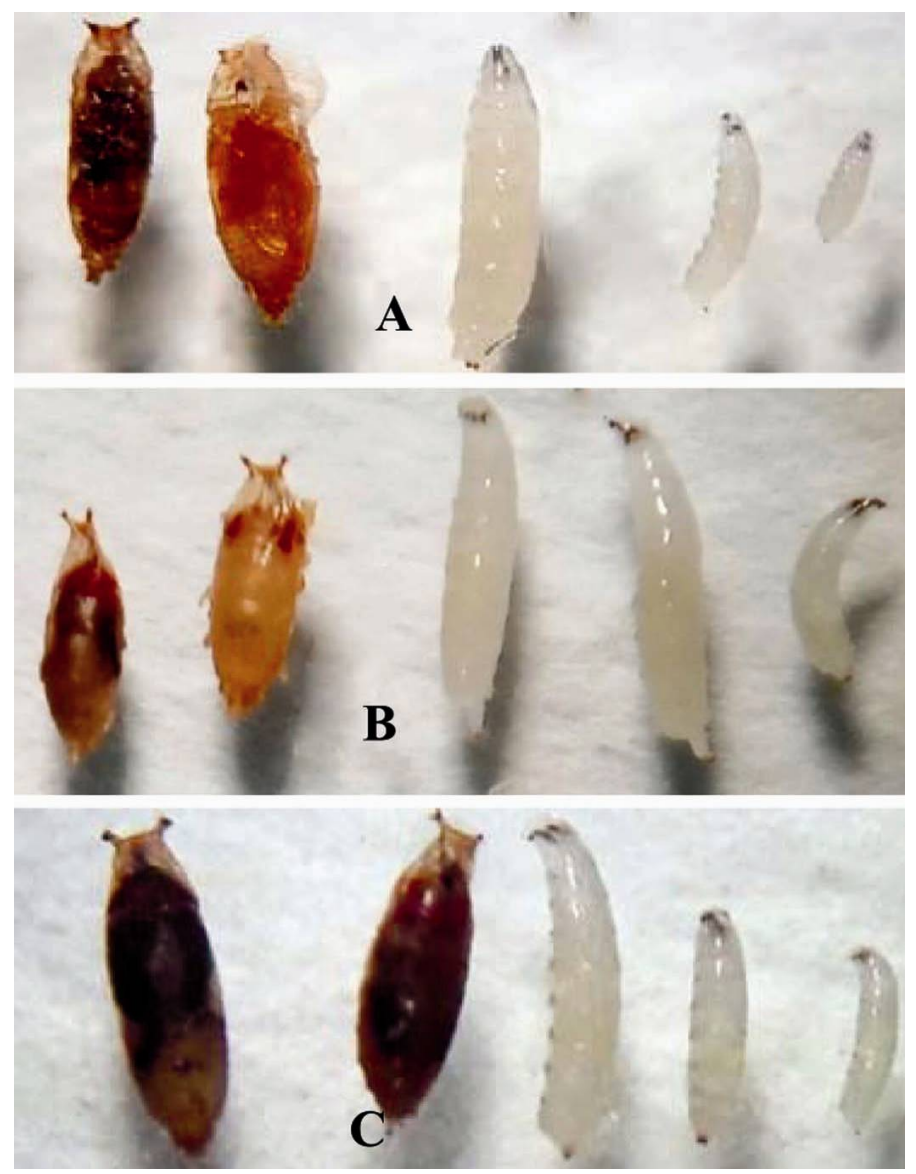

Fig. 3. Comparison among development stages of three Drosophila spp. A, B and C represents developmental stages of D. melanogaster, D. ananassae and D. bipectinata, respectively. 
5-8 teeth, lower one with 6-9 teeth and 1-2 teeth on distal part of second tarsal segment of the first leg(14). In D. bipectinata male, first tarsomere has proximal comb teeth no (4-7) and distal comb teeth no (6-10) and second tarsomere proximal comb teeth no 1-2 and no distal comb teeth ${ }^{(15)}$. Present findings of 5-7 proximal comb teeth and 5-8 distal comb teeth and 1-2 second tarsomere proximal comb teeth are in conformity with previous reports ${ }^{(14-15)}$.

Developmental stage (egg, larva and pupa) images of three Drosophila species strains are presented in the Fig. 3. Maturation time of D. bipectinata from egg to adult was longer than that of both $D$. melanogaster and D. ananassae. No difference in egg shape and size could be detected among three Drosophila species (Fig. 3). D. melanogaster egg length is reported to be $0.51 \mathrm{~mm}$ and width $0.18 \mathrm{~mm}$ and $D$. ananassae egg length $0.49 \mathrm{~mm}$ width $0.18 \mathrm{~mm}$, i.e. they are not significantly different between these two species ${ }^{(16)}$.

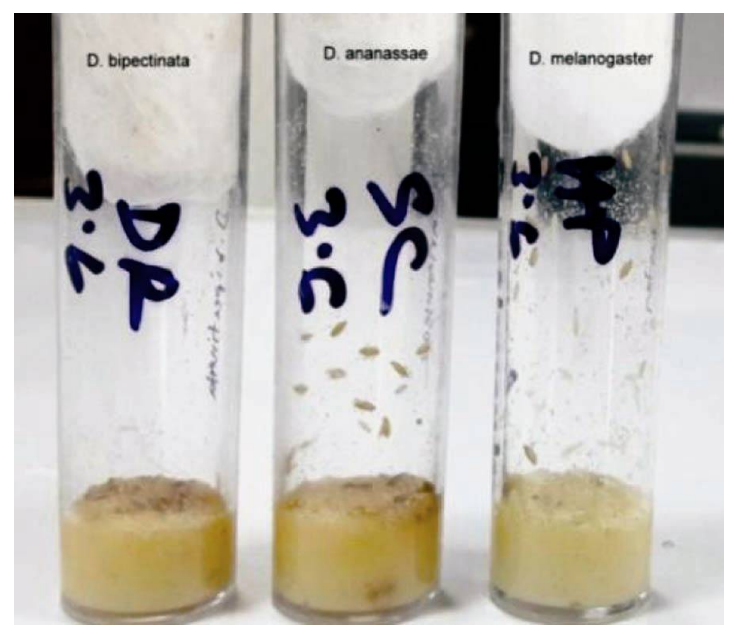

Fig. 4. Pupation height of three Drosophila species.

However, egg-laying site (oviposition site of the egg-laying female) differed in $D$. melanogaster and $D$. ananassae which laid eggs on the surface of the medium, while $D$. bipectinata laid eggs into the food medium (egg inserted into the medium). Each egg has two anterior dorsal appendages which are respiratory filament and one micropylar cone associated with an exochorionic surface of the larvae (First and second instars). The body length, shape and color of three Drosophila species were almost similar. However, the third instar larva of $D$. bipectinata was relatively larger than that of D. melanogaster and $D$. ananassae. Third instar larva of all but $D$. bipectinata crawls to the wall of the vial for a drier area to pupate. It preferred to stay on the food medium. No difference could be detected in pupa color, shape and size, but pupation sites differed. D. bipectinata pupation took place on the surface of the food medium, not on the wall of the vial. On the other hand, pupation in D. melanogaster and D. ananassae took place on the wall of the 
vial (Fig. 4). Differences in the pupation site among the three species have been observed when they were kept in the same condition with the same density, light and temperature. The same result was also reported in D. melanogaster which preferred to pupate on the vial walls ${ }^{(17)}$. However, the pupation site of $D$. bipectinata on the food surface is a finding of the present study.

\section{Conclusion}

Only three closely related Drosophila species have been studied here. Though the species are closely related to each other and belong to the same melanogaster subgroup, they have significant variation in some aspects. Diversity in sex comb teeth number and arrangement is a prominent one. Even, there is within-species diversity in terms of sex comb teeth number as found in D. bipectinata (Fig. 2C-O). Since the flies live in and around human habitat, the impact of environmental change on the fly life could be a reflection of the same on human. Thus, within and among species diversity in Drosophila could be utilized as a bio-indicator. Present work has provided baseline data that will be valuable in evaluating the influence of climate changes on biological system in future.

\section{Acknowledgement}

The authors are grateful to Professor Dr. Mohammad Ismail Miah of Chittagong University, Chittagong, Bangladesh and his research student Mr. Santosh Mazumdar for providing 3D imaging facility.

\section{References}

1. Powell JR 1997. Progress and Prospects in Evolutionary Biology. Oxford University Press, New York, pp.15.

2. Clark A, G Eisen, MB Smith, DR Bergman, CM Oliver, B Markow and TA Maccallum 2007. Evolution of genes and genomes on the Drosophila phylogeny. Nature 450(7167): 203-218.

3. Reiter LT, L Potocki, S Chien, M Gribskov and E Bier 2001. A systematic analysis of human disease-associated gene sequences in Drosophila melanogaster. Genome Res. 11 (6): 1114-25.

4. Rodríguez-Trelles F, MA Rodríguez and SM Scheiner 1998. Tracking the genetic effects of global warming: Drosophila and other model systems. Ecology and Society. 2(2): 2.

5. Chhabra R, S Kolli and JH Bauer 2013. Organically grown food provides health benefits to Drosophila melanogaster. PLOS ONE. 8(1).

6. Begum A and S Shaha 1973. Studies on the morphology and seasonal prevalence of local fruit flies. M.Sc. thesis, submitted at the Dacca Univ. p.130.

7. Sultana F 1998. Drosophilidae from Bangladesh. Drosophila Information Service 81: 149-150.

8. Markow T and P O'Grady 2006. Drosophila: A Guide to Species Identification and Use. Elsevier. pp. 259.

9. Kopp A and JR True 2002. Evolution of male sexual characters in the oriental Drosophila melanogaster species group. Evol. Dev. 4(4): 278-91.

10. Schawaroch V 2002. Phylogeny of a paradigm lineage: The Drosophila melanogaster species group (Diptera: Drosophilidae). Biol. J. Linn. Soc. 76(1): 21-37. 
11. Kopp A 2011. Drosophila sex combs as a model of evolutionary innovations. Evol. Dev. 13(6): 504-522.

12. Neha G and S Mohanty 2013. Sex comb variation in four Drosophila species from North India. IJBBR 4: 329-334.

13. Mcevey J, R David and L Tsacas 1987. The Drosophila ananassae complex with description of a new species from French Polynesia (Diptera: Drosophilidae). Ann. Soc. Ent. Fr. 4: 377-385.

14. Singh S and BN Singh 2001. Drosophila bipectinata species complex. IJEB 39: 835-844.

15. Mishra P K and BN Singh 2006. Unique phenotypes and variation in the sex comb patterns and their evolutionary implications in the Drosophila bipectinata species complex (Diptera: Drosophilidae). Eur. J. Entomol. 103(4): 805-815.

16. Markow T A, S Beall and LM Matzkin 2009. Egg size, embryonic development time and ovoviviparity in Drosophila species. J. Evol. Biol. 22(2): 430-434.

17. Casares P, M Carracedo and L García-Florez 1997. Analysis of larval behaviours underlying the pupation height phenotype in Drosophila simulans and D melanogaster. Genet. Select Evol. 29(5): 589.

Manuscript received on 30 October, 2018; revised on 12 February, 2019) 